\title{
The organizational culture of Iran University of Medical Sciences from the viewpoint of faculty members
}

\author{
Seyed Kazem Malakouti ${ }^{1}$, Fariba Karimzadeh², Sara Minaeian ${ }^{3}$, Azar Islami ${ }^{4}$, Mahdi Rezaei ${ }^{5}$, \\ Roshanak Ghods*6
}

Received: 27 Jul 2018

Published: 26 Apr 2019

\begin{abstract}
Background: It has been widely acknowledged that change and constant modification is the key to survive for any organization among their rivals. Since success in implementing changes in the organization strongly depends on the organizational culture, this study aims to assess the organizational culture in Iran University of Medical Sciences. The results of this study can be beneficial in initiating a movement towards the third - and fourth generation of universities.

Methods: This study is descriptive-correlational. The Organizational Culture Assessment Instrument (OCAI) was employed to collect data. A questionnaire was sent to the faculty members via email, and the responses were collected and analyzed.

Results: Out of the 982 faculty members, 189 participated (20.7\%) in this study. Analysis showed that the organizational culture of the university is congruent and harmonious and in the current state, it is primarily hierarchical (31\%) and market-oriented (28\%) with emphasis on stability and control in the organization. Whereas, faculty members tend to move the organizational culture of the university towards adhocracy $(30 \%)$ and clan culture $(29 \%)$.

Conclusion: University administrators must strengthen the culture of innovation and creativity based on the needs of the market. This only can be achieved by supporting teamwork in their move towards desired change.
\end{abstract}

Keywords: Culture, Organization, University, Faculty, Organizational culture, Third- and fourth generation universities, Hierarchical, Clan, Market-Oriented, Result-oriented

Conflicts of Interest: None declared

Funding: None

*This work has been published under CC BY-NC-SA 1.0 license.

Copyright $\subseteq$ Iran University of Medical Sciences

Cite this article as: Malakouti SK, Karimzadeh F, Minaeian S, Islami A, Rezaei M, Ghods R. The organizational culture of Iran University of Medical Sciences from the viewpoint of faculty members. Med J Islam Repub Iran. 2019 (26 Apr);33:35. https://doi.org/10.47176/mjiri.33.35

\section{Introduction}

\section{Definition of organizational culture}

New definition of organizational culture believes that culture is more than sharing information to reach a goal, it is more than a strategy, and thus more than generating and interpreting messages (1). Based on the thinkers' attitude

Corresponding author: Dr Roshanak Ghods,ghods.r@iums.ac

1. Mental health research center, Faculty of behavioral sciences and mental health Iran University of Medical Sciences, Tehran, Iran

2. Cellular and molecular research center, Iran University of Medical Sciences, Tehran, Iran

3. Antimicrobial resistance research center, Institute of immunology and infectious diseases, Iran University of Medical Sciences, Tehran, Iran

4. Central Library, Iran University of Medical Sciences, Tehran, Iran

5. Emergency medicine management research center, Iran University of Medical Sciences, Tehran, Iran

6. Research Institute for Islamic and complementary medicine, School of Persian medicine, Iran University of Medical Sciences, Tehran, Iran to the term of culture, there is a dual definition of organizational culture. Some focus on attitudes and some on the organizational behavior and function. Accordingly, some consider culture as a set of beliefs and values in an organization, and some take it as changes in the behavior and

\section{$\uparrow$ What is "already known" in this topic:}

The faculty members prefer adhocracy, innovation, and freedom for the features of dominant culture, leadership style and management of employee. They prefer trust, loyalty, and teamwork as the glue of organization. Conversely, they perceived the current organizational culture as a hierarchy and market. Furthermore, they believed that there is a discrepancy between marketing and adhocracy feature of the academic organization.

\section{$\rightarrow$ What this article adds:}

The existence of discrepancy between the perceived and expected organizational culture in faculty members' point of view, necessitates building a bridge to meet the organizational goals and vision in line which is achieving Third Generation of Universities. 
performance of individuals in the organization (1).

Organizational culture often acts as a vital factor in sustaining members of an organization (2). An organization with a strong culture helps its members to achieve satisfaction with their jobs by accomplishing and fulfilling their goals and duties. In other words, organizational culture determines the behavior and performance in the workplace (3). Given that organizational culture consists of shared values, beliefs, and members ideas of the organization (4), therefore, it cannot be regarded as a simple variable. Proper recognition of an organization's culture not only provides its members' conception of organizational functions and but also leads to the definition of norms and abnormalities (3).

Regardless of the attitude towards culture, every organization requires change and innovation in order to survive among its rivals (3). Change is always accompanied by deconstruction (4). Any change in the organization's performance, such as technology transfer, depends on the culture of the organization. Influenced by the national culture of the country, the organizational culture determines the success or failure of the technology transfer process (3).

Organizational culture is also a pivotal element in the effectiveness of an organization. Effectiveness is considered to denote accomplishing aims or manufacturing products. For example, a study conducted at a sports organization has shown that attention to organizational culture for entrepreneurship purposes is essential to the effectiveness of an organization (5).

\section{Types of organizational culture}

Various approaches have been applied to organizational culture. Cameron and Quinn (1999) highlighted adhocracy, clan, market, and hierarchy types of culture, while Denison (1990) divided organizational culture into four types of consistency, mission, involvement, and adaptability. Also, Cooke and Lafferty (1987) considered organizational culture to be constructive, passive/defensive, and aggressive. Some, including Charles Handy (1981), pointed to the four types of task, power, and person and role culture (6).

The four approaches described by Cameron and Quinn, Denison, Handy, and Cooke and Lafferty were compared in a critical view. The comparison was based on the six criteria of simplicity and intelligibility, the capability of applying varied research methods, ability to understand cultural changes, having a conceptual and theoretical framework, applicability in various organizations, and the recognition of privileged features (7).

Some studies have suggested Cameron and Quinn's model for research purposes, which focuses solely on understanding organizational culture. The Competing Values Framework (CVF) theory, proposed in the Cameron and Quinn' model, is widely used in organizational culture evaluations (7). Among the major models in the management science, the CVF model stands out as one of the most reliable approaches used for value creation. In this model, organizational culture is evaluated by different dimensions with the Organizational Culture Assessment
Instrument (OCAI) $(4,7)$.

In this model, culture is categorized into four different types: clan culture (human relations), adhocracy (developmental) culture, market (competitive) culture, and hierarchical culture (internal processes) (4). In the OCAI method, culture is classified into a matrix in terms of internal/external focus, and flexibility/stability and control (8).

1. The clan culture: Attention to the needs of employees and their participation in affairs form the main focus of this culture, which leads to an increased sense of responsibility and ownership in the members of the organization. Friendly environment, collaboration, orientation to teamwork, and attention to the identity of and commitment to employees are among the dominant values of clan culture. Leadership in this kind of organizational culture is facilitating and supportive, and success of the organization is defined as the fulfillment of organizational commitments and human resource improvement (4).

2. The adhocracy culture: In this culture, the attention and emphasis on internal stability and control are superseded by a focus on non-organizational issues. In addition to creativity and innovation, in this culture, learning and experiencing new methods are also developed. Accordingly, leadership in such organizations is a kind of an entrepreneurial, innovative, and risk-taking type; hence, achieving new products is one of the criteria of success for the organization (4).

3. The market culture: The focus of this culture is on the external environment of the organization, especially the market and stakeholders. A market-based organization is always looking for opportunities and threats to survive in a competitive market. In this organization, maintaining positive stakeholder relationship is one of the fundamental purposes. Therefore, leaders of such organizations pay special attention to products and achievements and define success in terms of reaching goals in competition with other rivals (4).

4. The hierarchical culture: Maintaining stability, control, and organizational integrity are some of the aspects of such organizations. Organizations characterized by traits such as the emphasis on compliance with laws and regulations, internal processes, direct control, and the existence of specific and measurable standards, are governed by a hierarchical culture. Leaders of these organizations are organizers and coordinators, and their criterion for success is adherent to rules and cost management (4).

Although there is no apparent "best" or "worst" among these four cultures and to some extent, most organizations are a combination of them; always there are one or two cultures that are distinctively governing the organization. The "right" culture for an organization at a certain time depends on what it generates or what it does, the position it has in its life cycle, the circumstances in which it operates, the position it holds in the market, and the source of its competitive advantage (4).

Based on these four cultures, various organizational culture assessment instruments have been developed and used in numerous organizations. Valuable results have been reported such as the association between organiza- 
tional culture and creativity and innovation, value creation, and job satisfaction. For example, in the nursing faculties affiliated with the Islamic Azad University, there has been a direct correlation between organizational culture and job satisfaction as well as leadership effectiveness (9).

Furthermore, the relationship between organizational culture and leadership styles was evaluated in a study conducted by a number of universities such as Tabriz, Tehran, Urmia, and Shahid Beheshti. Findings have shown that the effectiveness of management strongly depends on coordination between organizational culture and leadership style (10).

\section{The organizational culture of a university}

At the university level, culture can be considered as the values and beliefs of its stakeholders, including administrators, employees, students, and board members based on traditions and (verbal and non-verbal) communication (11). With a careful look at the architecture of the buildings, the maintenance of the campus, and student interactions, one may come to a relative understanding of the university culture. Therefore, the attention of the university administrators has increasingly been directed to the culture of the organization and its significant role in changing and developing the university. There is constantly an effective connection between the characteristics of a university and its culture (12). Unlike commercialbusiness organizations, universities often have difficult and vague goals to measure. In addition, not only internal stakeholders such as students, graduates, and experts but also external stakeholders such as associations, judicial organizations, accreditation offices, and their publications are very diverse while each plays an extraordinary role in organizational culture (8).

Le Feuvre and Metso have introduced three ideal models for academic culture in the areas of education and research based on the national culture and government policy for the organizational education sector of a university. One of these three models emphasizes on strengthening the innovation and creativity culture based on market demands supported by teamwork, and it has been known as the Anglo-American model. Another model, the Humboldtian model, is based on absolute freedom and generation of knowledge in universities as a result of combining education and research. In this model, the government only enforces the constitutional law. In the third model or the Napoleonic model, the basis is on the relative separation of education from research. The government monitors the management of higher education institutions in this model .Every part of the system, from curriculum to finance, is controlled by the government. In contrast, the Anglo-American model is based on the existence of integrated educational and research institutions which are completely independent and offer a wide range of activities and expertise in a completely free market. This model is based on the pragmatic approach and problem-solving logic and takes into account the needs of the community and markets of interest. Although universities which fol- low the Humboldtian model enjoy freedom and organizational autonomy, they may fail to pay sufficient attention to stakeholders' interests. Universities belonged to the Napoleonic model, are highly dependent on government control, whereas universities in the Anglo-American model, although entirely independent, are heavily considerate of their stakeholders (13).

Understanding the dominant organizational culture is the key factor to achieve success when undergoing any changes in an organization. Therefore, Iran University of Medical Sciences (IUMS) as a university with a wide range of cultures which plans to provide an ever progressing environment to train creative people and entrepreneurs conducted this study to evaluate the organizational culture of Iran University of Medical Sciences. To do so, researchers used the OCAI instrument, which is one of the most reliable organizational culture measurement tools. Research findings will benefit administrators of universities in their movement towards creating third- and fourthgeneration universities and will also act as a role model for other universities.

\section{Methods}

\section{Research Theoretical Model}

In terms of the methodological philosophy, this study is in the pragmatic and applied paradigm and in terms of data collection method, it is descriptive-correlational. In this study, Cameron \& Quinn's Organizational Culture Assessment Instrument (OCAI) was used to determine the cultural status in accordance with the framework of competitive values.

One of the most successful approaches that can be considered as a reference form to understand and evaluate organizational culture is the competitive values framework. There are various models that are based on the theoretical framework of competing values. Cameron and Quinn model (2006) have been Chosen and used in this research for the following reasons:

- In terms of measuring the dimensions and criteria of organizational culture, it seems perfectly aligned with the purpose of this study.

- It is practical to apply at different levels of the organization.

- It is used in over 1,000 companies around the world as it is one of the most successful tools for overestimation of organizational performances, and accurately helps in identification of important aspects of a fundamental culture of an organization (4).

- In this model, graphic drawings of the results are in forms of charts (like a radar) which can clearly illustrate the type of ruling current culture of the organization, as well as the desired and expected culture; therefore, allows to perform a systematic comparison between them.

- Distinctively identifies the components of the organizational culture which is essential for creating a change towards achieving a desirable outcome.

\section{Validity and Reliability}

There are different techniques for measuring the validity 
of the instrument. In this research, Cronbach's alpha method was used. The alpha coefficient for the questionnaire of cultural evaluation was $81 \%$, which indicates the validity of the chosen measurement tool in the studied population. In addition, OCAI is a well-known and widely used tool in the world and has been exerted in many organizations since 1999. Its widespread use and shown results has confirmed the validity of the chosen model and organizational culture assessment tools of this research.

The instrument holds 24 items, consisting of six subscales: 1. Dominant characteristics of the organization, 2. Organization leadership, 3. Management of employees, 4. Organizational glue, 5. Strategic emphases, and 6. Criteria of success. Each subscale has four options, and scoring involves a total score of 100 .

A questionnaire has been prepared and sent by email to all faculty members at the university. It was asked from participants to score the questionnaire twice. First, they were expected to select the scores to show the current status of the organization's culture and after that, they had to score it according to their preferred status of the organizational culture (8).

For data analysis, descriptive statistics were used in SPSS software (version 23), and to accurately describe the status of radar and spider charts, the Excel software was employed.

\section{Results}

\section{Demographics}

From the total number of faculty members of Iran University of Medical Sciences ( $\mathrm{n}=982)$, only $189(20.7 \%)$ responded to the sent email and completed the questionnaire. The survey showed that from 189 faculty members participating in this study, $47 \%$ were women and $53 \%$ were men and overall, $80 \%$ of the participants were married. Participant's age ranged from 25 to 55 and above and was arranged in four main age groups. The highest participation rate was in the age group of 36-45 years $(34.3 \%)$, followed closely by age group of $46-55(30.3 \%)$. The age groups of 25-35 had a response rate of $15.4 \%$, and the lowest response was belonged to the age group of 55 years and above $(13.3 \%)$. The percentage rates of tenure in the $1-10,11-20$, and $21-30$ age groups were $44.3 \%, 24.9 \%$, and $24.4 \%$, respectively, with the highest participation rate belonging to those with less than 10 years of tenure.

\section{Cultural traits}

The results obtained from the OCAI instrument are as follows:

\section{Dominant characteristics of the organization}

Findings in this section showed that from faculty members' perspective, the current status of the organization is hierarchical (32\%) and it has a bureaucratic and controlled environment. Typically, formal procedures govern employees' behavior, notwithstanding the fact that from employees' point of view the ideal outcome is to achieve the adhocracy culture (38\%) and obtain a dynamic and entrepreneurial environment in the university where faculty members tend to be risk-taking to enhance the university culture (Fig. 1).

\section{Organizational leadership}

Findings of this section indicated that, from the viewpoint of faculty members, the organizational leadership in the current state is largely market-based (32\%). They stated current leadership is strong, bold, and resultsoriented, while they expect an adhocratic leadership (developmental) (32\%) with greater entrepreneurial, innovative, and risk-taking characteristics. Employees prefer to work in an environment where collaboration is promoted more than competition culture (Fig. 2).

\section{Management of employees}

Based on the analysis of the questionnaire, faculty members stated that current management of employees primarily borders on a market type (competitive) (34\%). They expressed that this management style creates a sense of competition and forms high expectations in attaining results among employees. However, faculty members expect to be allowed to act as an individual in risk-taking, innovation, freedom of action, and uniqueness (29\%) (Fig. 3 ). They demand for a creative and solidary management rather than competitive and results-oriented management which its priority is attention to the market.

4. Organizational glue

It has been presented by findings of this research that,

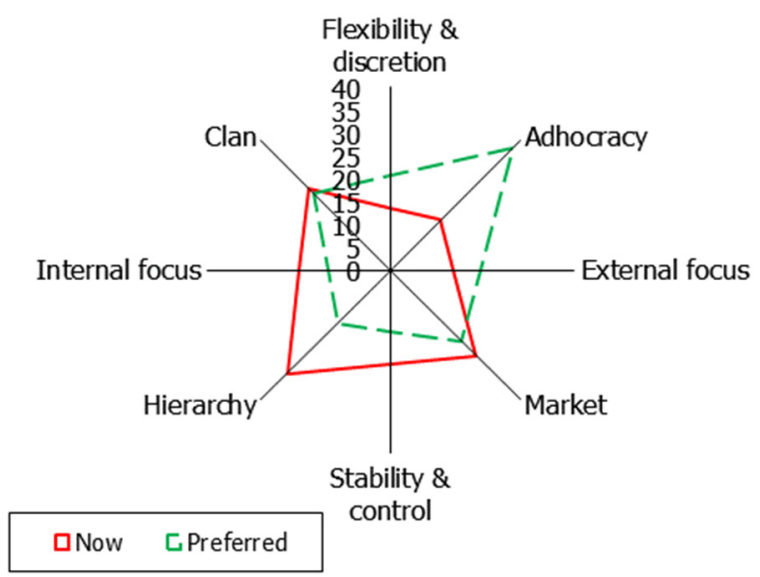

Fig. 1. Dominant characteristics of the organization in the current and preferred states

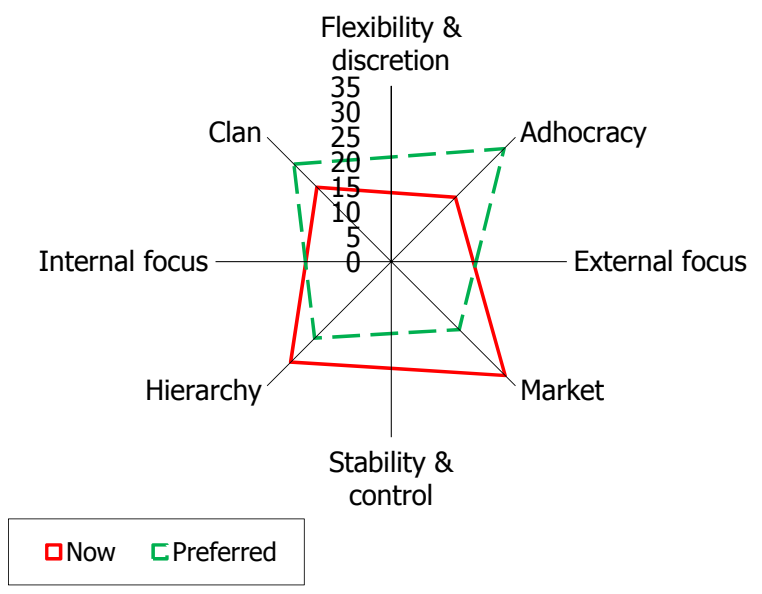

Fig. 2. Organizational leadership in the present and preferred states 


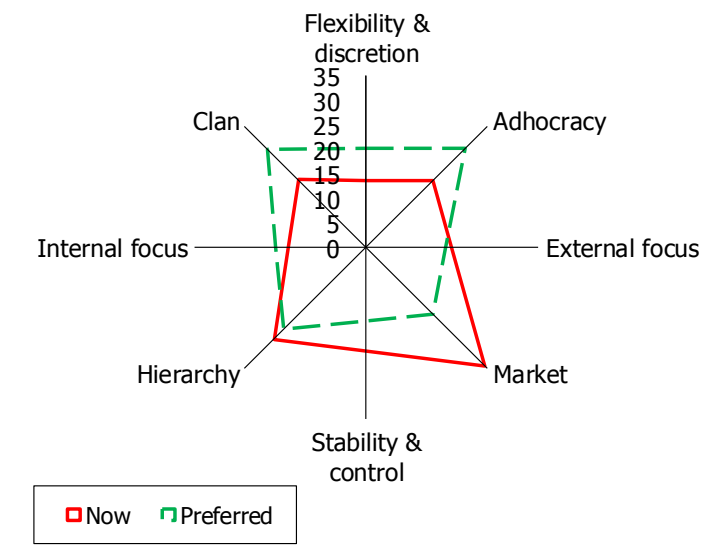

Fig. 3. Management of employees in the current and preferred states

organizational glue of the university in the present state is mainly of a hierarchical and bureaucratic type (34\%). In the viewpoint of faculty members, factors that bind components of the university are rules and policies. They also remarked that maintaining the smooth function of the university is one of the major concerns of current culture, whereas employees expect loyalty, mutual trust, and teamwork conscience hold the elements of the university together. These attributes denote the clan type of organizational culture (32\%) (Fig. 4).

5. Strategic emphases in the organization

The findings showed that, in the present state, the university follows a hierarchical organizational culture $(32 \%)$. The faculty members stated that the university emphasizes on stability and efficiency, control, and the smooth function of the system are of significant importance for the university. However, the faculty members envisage a university that emphasizes on the acquisition of resources and creation of new challenges. They expect innovation and search for new opportunities at the university to be worthwhile and high confidence, transparency, and participation be present in the culture. These attributes denote the approved organizational strategy in the adhoc-

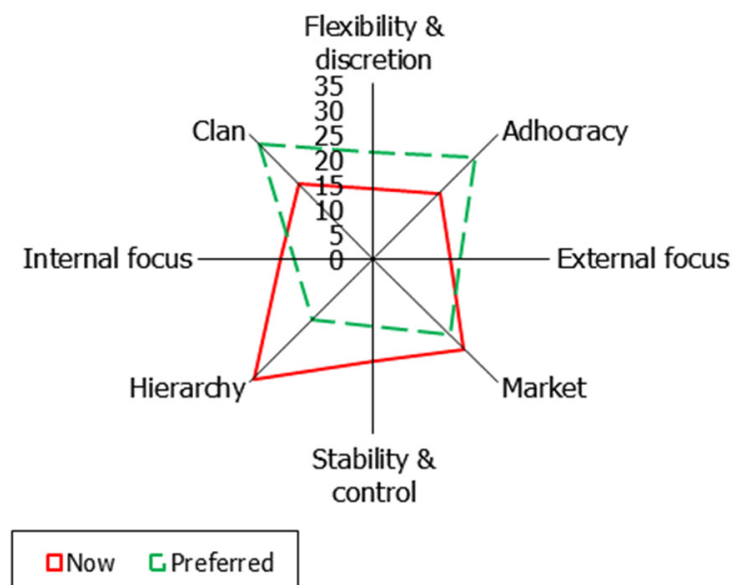

Fig. 4. Coherence (glue) of the organization in the current and preferred states

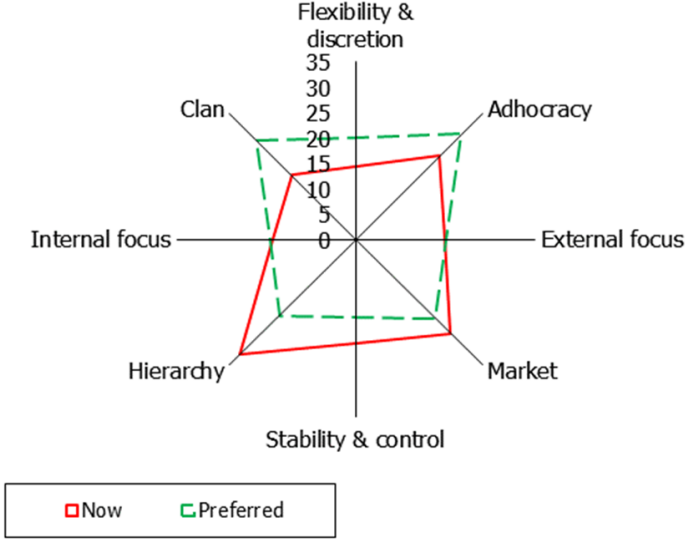

Fig. 5. Organization's strategic emphases in the present and preferred states

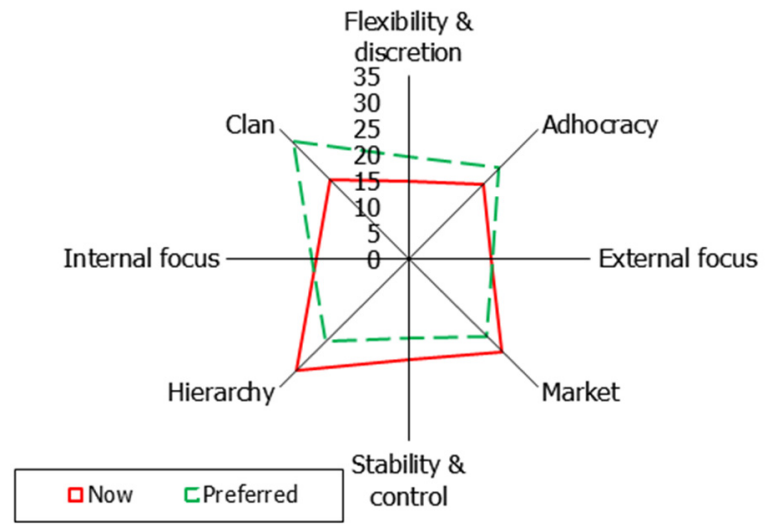

Fig. 6. Criteria of success in the present and preferred states

racy $(29 \%)$ and clan (28\%) organizational cultures (Fig. $5)$.

6. Criteria of success

The findings showed that faculty members' perspective, the criteria of success in this university are determined by effectiveness. Reliable services, smooth planning, and low costs are also of great importance. This view is consistent with the hierarchical organizational culture $(30 \%)$. Nevertheless, the faculty members believe that human resource development, teamwork, conscientiousness, and respect for demands of the community should be recognized as the criteria of success at the university. This type of attitude corresponds to the clan culture (32\%) (Fig. 6).

\section{Discussion}

This study was designed to evaluate the organizational culture of faculty members of Iran University of Medical Sciences. Of 982 faculty members, despite frequent notification, only 189 completed the questionnaire and replied to the sent email. Clearly, the result of examining this number of questionnaires cannot be generalized to the entire faculty of the university; however, due to the limited similar studies in this field, especially in Iran, the results of this research seems to worth reporting as it can be beneficial for future studies with larger sample sizes.

The low response rate of about $20 \%$ can make the generalizability of the results difficult; Nevertheless, interest 
in such questionnaires and willingness to respond, as well as reliance on change according to the Pareto principle (14) are subsequent to the activity and impact of twenty percent of the faculty members. Most of the participants in the study were middle-aged faculty members with a working experience of less than ten years. It indicates that new faculty members were more interested in research projects about incremental plans of their university. Thus, the future plans should pay more attention to enthusiasm and capability of new faculty members in developing macroprojects of the university. However, protagonists should encourage employees to be more attentive about the new aspects of improvement of their university.

The final analysis of the findings obtained from the OCAI instrument showed that the overall organizational culture in Iran University of Medical Sciences is congruent and harmonious culture because almost every six examined items are in the same quadrant of the chart. In the current state, the university's organizational culture is largely hierarchical (bureaucratic) (31\%) and marketbased (results-oriented) (28\%). However, faculty members prefer the organizational culture of the university move towards adhocracy and clan culture $(30 \%$ and $29 \%$, respectively) (Fig. 7).

Meanwhile, given the fact that according to the results obtained (Table 1), the necessity of change is evident based on the discrepancy between the current and the preferred states, and also with respect to the fact that the difference above 10 is significant (8); transition towards a developmental culture with reduced bureaucratic processes in the university is necessary, and it requires taking appropriate action by university administrators.

Moreover, according to the results obtained, it is concluded that reinforcing the supportive organization and reducing the focus on results-oriented and market-based processes are the demands of the faculty members, which are themselves controversial and demands further interpretation.

\begin{tabular}{|c|c|c|c|}
\hline \multicolumn{2}{|c|}{ Internal focus - } & $\begin{array}{l}\text { y \& } \\
\text { on }\end{array}$ & nal focus \\
\hline \multicolumn{4}{|c|}{ Hierardhy' } \\
\hline \multicolumn{4}{|c|}{$\begin{array}{c}\text { Stability \& } \\
\text { control }\end{array}$} \\
\hline \multicolumn{4}{|c|}{$\begin{array}{l}\text { Fig. 7. Total IUMS organizational culture according to the OCAI } \\
\text { instrument }\end{array}$} \\
\hline \multicolumn{4}{|c|}{$\begin{array}{l}\text { Table 1. Overall organizational culture in IUMS from the viewpoin } \\
\text { of faculty members }\end{array}$} \\
\hline Indicator & Now & Preferred & Discrepancy \\
\hline Clan & 21 & 29 & 8 \\
\hline Adhocracy & 19 & 30 & 11 \\
\hline Market & 28 & 21 & 7 \\
\hline Hierarchy & 31 & 21 & 10 \\
\hline
\end{tabular}

Mozaffari et al. conducted an extensive study in nine universities in Iran in 2008 and assessed the discrepancy between the current organizational culture of Iranian higher education institutions and the preferred culture. The study states that the universities primarily have a culture of control and stability, where bureaucratic rules and policies are dominant, and so they are generally outcomedriven and highly competitive. These findings are comparable to the results of this study. It is evident from the study that despite the fact that the deans of colleges and heads of departments in these nine universities considered developmental organizational culture as the most efficient and desirable type of culture for educational institutions and universities; the governing policy of universities did not change from 10 years ago. Clearly, transition to third or fourth generation universities occurs when the old methods can be modified. In fact, university culture should emphasize on flexibility, participation, autonomy, human resource development, creativity, and innovation in risk-taking. Culture also should include long-term goals on professional development and acquisition of new professional knowledge and skills (10).

In a study conducted at one of the non-governmental universities in 2013, it was also found that the current organizational culture of the university was primarily hierarchical $(33.02 \%)$ followed by a market-oriented (competitive) culture (25.17\%). Nevertheless, the preferred culture is of the clan type $(31.75 \%)$ followed by the developmental type $(27.77 \%)(15)$. The findings of this study are highly consistent with the results of the present study and emphasize on the necessity of fundamental changes in methods and subsequently of managers.

In the governmental organizations in Tehran, the findings have shown that the governing culture in these organizations is more of a bureaucratic characteristic, where respect for the organizational hierarchy in carrying out the assigned activities and supervision of managers on the respective units are highly emphasized. Therefore, it is very hard to welcome challenging situations and provide an appropriate context to create new opportunities in such organizations (16). The findings of the mentioned study and the present study are comparative and showed that most Iranian governmental organizations have a hierarchical culture.

In another study, 226 faculties, 261 employees, and 375 students were studied at Shiraz University through randomized stratified sampling to assess the organizational culture of the university using the OCAI instrument. The results showed that the dominant culture from the viewpoint of professors and employees was clan type and from the viewpoint of students, it was hierarchical type (17).

In order to compare Iran with other countries, several researches in the similar subject have been chosen and evaluated. For instance, two studies from Indonesia (18, 19), showed that in contrast to our study, 38 employees in one of the non-governmental universities in 2013 stated that clan culture is the dominant culture in both current and desired states of their university (18). However, in another study, 7 research laboratories affiliated with the 
University of Indonesia were studied, and the current organizational culture of four of them were clan type, two of them were market type, and one of them was developmental type, whereas the desired organizational culture in all of these seven laboratories was the clan type (19).

In the Department of Sports and Health at the Rowan University of New Jersey in 2007, results of a general analysis of OCAI tool indicated that the dominant culture of this department in both the current and desirable states was the clan culture. In other words, students found their department in its current state as a friendly and family-like environment and their teachers have the role of mentors. In their department, respect for tradition, loyalty, and accountability were of particular value and employees were encouraged to continue to do so. The findings of this study correspond to the desire for a clan organizational culture (8).

In the University of Ege in Turkey, the experience was similar to our case in Iran. It was found that organizational culture in the current state was largely hierarchical followed by market-based, while the strategic objective of this university was to achieve a developmental and clan organizational culture with a partly market-oriented nature. This showed that there is a discrepancy between the goals and strategies of the university and the present state of organizational culture, while scholars in the field of organizational culture believed that the mission, goals, and strategic activities of an organization should not be in conflict with each other (20). Russian student at the Economics University of Plekhanov stated that the current organizational culture of the institution was hierarchical, believing that the university had an uncompromising structure strongly controlled by the chancellor. They expressed that all activities in university are governed by laws, regulations, and procedures, while they preferred to experience diminishing role for the governing hierarchical culture. The findings of this study were consistent with those of the present study in terms of stakeholders' desire to change from hierarchical culture to other cultures (21).

Previous studies demonstrated that clan and resultsoriented organizational cultures, similar to the developmental organizational culture, had a direct correlation with creativity and innovation, whereas a hierarchical organizational culture will not initiate innovation and creativity (22) and correlates reversely with job satisfaction (23). In the United States' institutions, a high degree of acceptance of clan culture and a low acceptance of results-oriented cultures among the staff has been observed (24). Research results from the University of Ohio also suggest that clan culture is more effective than other cultural models in the college (25).

As the results of this study demonstrate, in the current state, the bureaucratic and result-oriented (market-based) characteristics dominate Iran University of Medical Sciences. While the preference of the faculty is developmental and clan culture, market-oriented culture is not welcomed by them. This finding is not consistent with the university's strategy of shifting the paradigm to a thirdgeneration university. Leading the university to produc- tion, marketing, wealth and value creation is among the principles of the new paradigm, which requires a resultsoriented and market-oriented culture, while the results of this study showed that this is not the university faculty members' desired attitude.

\section{Conclusion}

The employment of organizational culture measurement tools helps organizations to identify the strengths and weaknesses of their organizational culture. Moving towards the teamwork model in an innovative and entrepreneurial environment can lead to solidarity as well as entrepreneurship and creativity at the university. However, without the reinforcement of the market-based culture, the main goal of the third-generation university such as producing and creating value and wealth is not realized. Therefore, it is necessary to strengthen a culture at the university that is developmental, market-oriented, and consists of clan components. Failing to do so will result in products that do not meet the needs of society and ultimately leads to solely generate scientific research publications in scientific journals lacking productive outputs for the society. It seems that in advancing towards creating change in university's culture, we need to strengthen the culture of innovation and creativity based on market demands; In addition, it should be supported by teamwork, as proposed by the Anglo-American model (13).

\section{Acknowledgments}

The authors of this article appreciate all faculty members of Iran University of Medical Sciences, who helped the members of the research team by completing the forms and answering questions patiently. We also sincerely thank the efforts of Mr. Shahram Gholizadegan who helped us with executive issues.

\section{Conflict of Interests}

The authors declare that they have no competing interests.

\section{References}

1. Driskill GW. Organizational culture in action: A cultural analysis workbook: Routledge; 2018.

2. Naranjo-Valencia JC, Jiménez-Jiménez D, Sanz-Valle R. Studying the links between organizational culture, innovation, and performance in Spanish companies. Rev Lat Am Psicol. 2016;48(1):30-41.

3. Safardoust A, Mohammad Rozesara M, Naghizadeh M, Manteghi M. Reviews the Role of Organizational Culture from Hofstede's Model on the Effectiveness of Technology Transfer. Quarterly Socio-cult Dev Stud. 2016;4(4): 169-184.

4. Cameron KS, Quinn RE. Diagnosing and changing organizational culture: Based on the competing values framework: John Wiley \& Sons; 2011.

5. Amoozadeh Z. The Relationship of Organizational Culture and Entrepreneurship with Effectiveness in Sport Organizations. Ann of Appl Sport Sci, 2014;2(3):51-60.

6. Alvesson M, Sveningsson S. Changing organizational culture: Cultural change work in progress: Routledge; 2015.

7. Mihaela V, Bratianu C. Organizational culture modeling. Manag Market. 2012;7(2):257.

8. Fralinger B, Olson V. Organizational Culture at the University Level: A Study Using the OCAI Instrument. J Coll Teach Learn. 2007;4(11):85-98.

9. Arasteh H, Salimi M. Developing a model for leadership 
effectiveness in nursing colleges at Islamic Azad University. Quart J Nurs Manag, 2013;2(2):19-29.

10. Mozaffari FA, Pardakhtchi M, Sorkhabi MYD, Zokaii M. A Study of Relationship between Organizational Culture and Leadership Styles in Iranian Institutes of Higher Education. Q J Res Plan in High Educ. 2008;14(1):133-57. (Persian).

11. Bartell M. Internationalization of universities: A university culturebased framework. High Educ. 2003;45(1):43-70.

12. Ji-sheng W. Scientific connotation of university culture. J High Educ. 2005;10:001

13. Lacatus ML. Organizational culture in contemporary university. Procedia-Soc Behav Sci. 2013;76:421-5.

14. Koch R. The $80 / 20$ principle: the secret to achieving more with less: Crown Business; 2011.

15. Hamidifar F, Vinitwatanakhun W, Rahnamay Roodposhti F. Developing Int J Manag Business Res. 2013;3(2):161-74.

16. Rasteh moghadam A, Rahimian H, Abbaspour A. Identifying the challenges of organizational culture and proposed methods for its change: Case study of governmental organizations in Tehran. Organ Cult Manag J. 2013;11(4):111-35.

17. Dadgar H, Marzooghi R, Torkzadeh J, Mohammadi M, Barahouei F. A comparative evaluation of the perception of lecturers employees and students about the organizational culture of Shiraz University. Life Sci J. 2013;10(1):441-8.

18. Simamora BH, Jerry $\mathrm{M}$. Current and preferred organizational culture: A case study at private university in Indonesia. Int Bus Manag. 2013;7(4):353-8.

19. Akmaliah IF, Sensuse DI, Wulandari IA, Nurrohmah I, Imanda R, Cahyaningsih E, et al. editors. Analyzing knowledge management in research laboratories based on organizational culture. Science in Information Technology (ICSITech), 2017 3rd International Conference on; 2017: IEEE.

20. Beytekin OF, Yalçinkaya M, Doğan M, Karakoç N. The organizational culture at the university. Int J Educ Res. 2010;1(2):113.

21. Vasyakin BS, Ivleva MI, Pozharskaya YL, Shcherbakova OI. A Study of the Organizational Culture at a Higher Education Institution [Case Study: Plekhanov Russian University of Economics (PRUE)]. Int J Environ Sci Educ. 2016;11(10):11515-28.

22. Ashraf G, Abd S, Kadir, Akmaliah Z, lope pihie Z, Rashid A. Relationship between Organizational Innovativeness Types and Organizational Effectiveness in Private Universities in Iran. J Stud Educ. 2014;4(1):143-53.

23. Dimitrios B, Kastanioti C, Maria T, Dimitris N. The influence of organizational culture on job satisfaction of administrative employees at a public hospital: The case of General Hospital of Larissa. J Health Manag. 2014;16(2):217-31.

24. Abbassi Z, Prirokh M, Dayyani MH, Fattahi R. Corporate Culture Prevailing on University Central Libraries and its Impact on the Extent of Knowledge Management Implementation. J Inf Process Manag. 2010;25(3):389-412.

25. Berrio AA. An organizational culture assessment using the competing values framework: A profile of Ohio State University Extension. Age. 2003;2(699):1.052. 